\title{
3. Problems of Temporality in the Digital Epoch
}

\author{
Yuk Hui
}

\begin{abstract}
This essay approaches the question of time by considering how digital media have reconstructed the relations between past, present, and future. It proposes that the past and present are becoming more and more determined by future events that have not yet happened but are paradoxically already there. Building on Bernard Stiegler's analysis of primary, secondary, and tertiary retention, it argues that the missing term in current understandings of time is tertiary protention, or the phenomenon of preemption.
\end{abstract}

Keywords: philosophy of technology, preemption, interobjectivity, time, futurity, China

I have chosen a monstrous title, "Problems of Temporality in the Digital Epoch," in that it is difficult if not impossible to treat the subject of temporality in general because every attempt to clarify temporality inevitably becomes lost in confusion, as Saint Augustine once said in his Confessions: "What then is time? If no one asks me, I know what it is. If I wish to explain it to him who asks, I do not know." Every attempt to seize hold of what time is leads to ekstasis, or being outside of itself, which recursively extends to the indefinite. I do not intend to construct an ontology of time here, since it will be doomed to failure; but concerning the monstrosity of the concept of temporality, I also cannot let complacency triumph by taking for granted the present transformation of temporality. Therefore, I would like to talk about problems here. To focus on these problems, I will discuss only individual time and historical time, limiting myself to the question of the future. If I posit the future as a sphere of problems (with the understanding that for

Volmar, A. and K. Stine (eds.), Media Infrastructures and the Politics of Digital Time: Essays on Hardwired Temporalities. Amsterdam: Amsterdam University Press, 2021 DOI 10.5117/9789463727426_CHO3 
certain people the future is always a problem on account of its uncertainty), it is because I would like to suggest a need to strike free from such futures, which is nothing posthuman but too human.

\section{Orders of Temporal Magnitude}

In general, we can approach the question of time in terms of a threefold temporality, namely past, present and future, according to different orders of magnitude. In the first instance, we understand time from an objective geometrical point of view, that is to say, the spatialization into geometrical form divided by second, minute, and so on so forth. For the ancient Greeks, time is thus characterized as "between" (metaxu); for the Stoics, it is "interval" (diastama); and for Augustine, it is sentimus intervalla temporum. In the second case, we approach time in terms of living experience, in which its thickness cannot be reduced to geometrical points but rather must be grasped as indivisible totality, for example, what Henri Bergson calls durée. Lastly, we approach time from the perspective of history, as a past that we have never lived but that belongs to us and remains the condition of our experience. Rather than being merely different points of view, however, these notions of time correspond to different orders of magnitude. ${ }^{1}$ Between these different orders of magnitude, as I argue, we can locate forms of technological mediation that complexify what Heidegger calls the temporalization of past, present and future. In turn, this means that the mediation between these orders of magnitude is subject to an analysis of the evolution of technology.

This brings us to the modes of mediation in the digital epoch. Digital technology has brought a tremendous challenge to the previous understanding of time by reconstructing the relations between these orders of magnitude. For example, we know that with digital technology it is possible to divide a second of sound into milliseconds of microsound, as demonstrated by the granular synthesis of Curtis Roads and Iannis Xenakis. ${ }^{2}$ Such works open a new relation to indivisible human experience, in that a listener is not be able to perceive the millisecond as an individual sound but instead hears only the whole that is already synthesized, as when Leibniz says that when we hear the roar of the ocean, we do not perceive the petites perceptions of the wave but only a synthesis en gros. Nevertheless, in and between these two orders of magnitude, that is to say, in and between the micro and the phenomenological, interobjective relations can be established through digital technology that are available 
to visual display. By interobjective relations I mean those relations that exist independently of associations made by the human mind and that are rather discovered in their constant process of materialization according to new epistemologies and technologies. In On the Existence of Digital Objects, I tried to demonstrate that the history of technology could be considered as a series of discoveries and masteries of interobjective relations (or discursive relations). ${ }^{3}$ In this sense, we can see that temporality is always material; it is hardwired in the technologies that constitute it, and this process of hardwiring will continue indefinitely. Interobjective relations in their prevailing form today - data - are those which reconstitute the dynamic of temporalization.

This brief summary is meant to show that technological evolution alters the question of temporality precisely because it constitutes new interobjective relations that penetrate into different orders of magnitude that have hitherto been unrealized. It is not that technology reconfigures physical time; rather, it brings about new dynamics in what we might call, following Heidegger, the temporalization of past, present, and future. My emphasis, as mentioned, will be on the future. I would like to put my arguments in a simple proposition: our past and present are becoming more and more determined by future events that have not yet happened but are paradoxically already there. The future is a temporality that exceeds what is "hardwired"; however, "being hardwired" remains its most important condition (this is the reason I distinguish discursive relations from existential relations).

The ultimate future for every individual is of course death; the ultimate future of humankind is the solar explosion. But it is also limits that give weight and meaning to temporality instead of pure becoming. Human being anticipates its own death, which is a future already given and is called destiny. Such is Martin Heidegger's famous notion of being-towards-death, in which the philosopher ties finitude to the authenticity [Eigentlichkeit] of human existence, which he calls Dasein. Heidegger's privileging of authenticity consists of two gestures: first, he emphasizes the privation of the They [das Man], a fictional future that separates Dasein from its own time; second, he understands time as self-constituting, by affirming a future that is transcendent, namely death, and refusing a future that blinds Dasein from truth. ${ }^{4}$ However, at stake is the exact nature of this limit. The digital epoch, as I want to argue, is characterized precisely by this fictive futurity, not only because the gap between the world and science fiction is diminishing but also because the future is becoming a metaphysical force and is in the process of liberating itself in all domains. 


\section{The Problem of Tertiary Protention}

Today, technological development, with the combination of big data and predictive algorithms, has rendered what I call tertiary protention more visible and made the relation between the future and the They more explicit than ever. In Husserl's phenomenology of time-consciousness, he distinguishes primary and secondary retentions and protentions. ${ }^{5}$ To assist this with an example, let us consider Johann Strauss's An der schönen blauen Donau. When I listen to the piece for the first time, I retain every now of the melody because every now is always no longer; this is called primary retention. At the same time, I also anticipate the coming melody, without which I would be unable to comprehend the phrasing and would hear not music but only sound; this anticipation of the coming "now," the "not-yet," is primary protention. If tomorrow, I remember the Blauen Donau, it is no longer a temporarily retended "now" but rather a recollection, namely, a memory or secondary retention; and since I already have memory of the music, I am able to anticipate the end of every phrase and the end of the piece as well, as secondary protention. Building on Husserl's concepts of primary and secondary retention, Bernard Stiegler has suggested what he calls tertiary retention, or artificial memories. ${ }^{6}$ For example, my secondary retention of the Strauss piece is not reliable in that it vanishes over time, but a CD may help me to recover that memory. The gramophone (analogue) and the $\mathrm{CD}$ or now $\mathrm{MP}_{3}$ (digital) are tertiary retentions that in some way invoke our primary and secondary retentions and protentions like Proust's madeleine. I propose to add to this schema a tertiary protention, a form of anticipation that is no longer my own subjective projection but rather a projection that is imposed on me and proceeds ahead of me. Protention cannot be reduced to any form of retention or any combination of retentions because protention is ontologically different from retention. Otherwise, there would be no différance, in the sense of Derrida, because différance is the "retention and protention of differences." I argue that tertiary protention is the missing term necessary to bring forward a full hermeneutic circle and analysis of the contemporary politics around attention, desire, and capital.

Everyone using social media knows very well that we are dealing with recommendations all the time, as if the future was always already present in the form of multiple choices. A typical example used for decades by computer scientists working in the field of ubiquitous computing is the following: you just finished work and are feeling tired while driving home, and when you arrive, you find a cup of warm, freshly brewed coffee waiting for you, with exactly the type of coffee bean you have in mind. This example 
is only the tip of the iceberg of the increasing power and phenomenon of tertiary protention, described by many as preemption. Through preemptive algorithms, we are witnessing a mode of marketing based no longer only on psychoanalysis, as what Edward Bernays, the father of public relations and nephew of Sigmund Freud, used, but rather on detailed statistical study of behaviors in order to capture the future through the past and impose it on the present. Here, we observe the repetition of the future, functioning as a new synthesis apart from those Gilles Deleuze analyzed in Difference and Repetition. ${ }^{8}$ Deleuze discusses three syntheses of time: the Humean repetition of habits, the Freudian return of trauma, and the Nietzschean eternal recurrence of the same in which the future is already at the present. In this fourth synthesis of time that we call tertiary protention, the future is also at the present, but it does not carry the same sense as Deleuze's third synthesis; in fact, it is a return to a mode of repetition that is complex but mechanical and homogenous. In our digital milieu consisting of smart objects, smart homes, smart cities, and social networks, the time of each individual is fragmented and reorganized so that tertiary protention is ahead of us.

What could have been called an insight decades ago is today no more than common sense in view of the becoming of technical systems. (I take the term "system" here in the sense of Jacques Ellul, who in the 1970s already clearly described the totalization and autonomy of a technical system in view of the computer's capacity for data processing. ${ }^{9}$ ) In On the Existence of Digital Objects, I suggest to liberate time from the increasing threat of the determination of tertiary protention by inventing new temporal organizations through creation of alternative technological architectures and algorithms. ${ }^{10}$ This involves fundamentally a reorganization of interobjective relations. For example, from 2011 to 2012, I worked with the computer scientist Harry Halpin to develop a prototype of a social network based on groups instead of individuals, with each group being based on a common project and each project referring also to a projection, or an investment of time. ${ }^{11}$ Additionally, in 2013, I worked with a group of computer scientists from Princeton University and Deutsche Telekom Laboratory to propose a new recommender system based on groups. If the new form of interobjective relations has already acted upon us in our daily lives and constitutes what Antoinette Rouvroy calls "data behaviourism," then it extends much further than individual time, constituting instead a collective imagination of the future. ${ }^{12}$ It is because of this futurality powered by the algorithmic processing of data that I would like to proceed to the second problem concerning our collective past and its becoming, which we call world history. 


\section{The Problem of the Digital Future}

It is not only "personal time" that is hardwired but also historical time. Through the hardwired geometrical time that we call synchronization, we arrive at a historical time that we call globalization. It is in the axis of time in which the historical temporalities of all cultures converge that we can articulate a world history. The danger of synchronization is that with digital technology, especially the data economy, we are all moving towards one future, the pinnacle of humanism. This future is associated with technological singularity, artificial intelligence, machine learning, and the realization of the homo deus. Yuval Noah Harari, the author of Homo Deus, embraces a human-algorithm reduction, proposing in the name of "life science" the following:

1. Organisms are algorithms, and humans are not individuals - they are 'dividuals,' i.e. humans are an assemblage of many different algorithms lacking a single inner voice or a single self.

2. The algorithms constituting a human are not free. They are shaped by genes and environmental pressures, and take decisions either deterministically or randomly — but not freely.

3. It follows that an external algorithm could theoretically know me much better than I can ever know myself.... Once developed, such an algorithm could replace the voter, the customer and the beholder. Then the algorithm will know best, the algorithm will always be right, and beauty will be in the calculations of the algorithm. ${ }^{13}$

The transhumanist tone, claiming insight from "life science," has already pointed to a future of humanity that can be reduced to an artificial intelligence governed by a super intelligence, which knows anything and everything. This is a future that will arrive at us. Questioning the "we" is delicate in that we may easily fall into one of two sides. One is ethnocentrism and ethnofuturism, which often fall prey to proto-fascism. The other is a universalism that affirms the realization of humanity through technical advancement. But it is because of the delicacy of this question that I think we cannot avoid it in our reflection on the digital future or futures, lest we lose sight of the issue of locality. To tackle this question, we will need to reassess the history of technology and challenge the universalist conception of it. I use the term "universalist" to refer to the unreflective belief that there is only one type of technology, no matter if it is Chinese, Indian, Amazonian, or European, with differences among these contexts being ascribed to levels of advancement. Nevertheless, it is by the advancement of technology that the future merits its name. 
Therefore, I will go a step further to suggest that we must liberate ourselves from this deterministic view of history in the digital epoch, called forth by transhumanist futurisms and prometheanisms, such as accelerationism. The problem is not that the transhumanist's proposal of immortality or a-mortality problematizes the "being-towards-death" of Heidegger; rather, the realization of the homo deus, or technological singularity, as end of history expresses the desire and the delirium of the modern. This competition for technological singularity will characterize the geopolitics of the coming decade. Technological competition, which historically took shape largely as military competition, has now become a domestic competition in terms of automated technologies, artificial intelligence, deep learning, nanotechnologies, and genetic technologies that define the sovereignty of the nation state. China released a whitepaper in August 2017 that states its wish to become the leading country in AI by 2030, with AI being introduced into primary school education and onward in the meantime. In September 2017, Russian President Vladimir Putin gave a speech to the Russian children in which he proposed that "whoever leads in AI will lead the world." Earlier, during his 2016 US presidential campaign, Donald Trump proposed to bring back jobs that China had "stolen," which could only be done, as some economists suggested, by implementing automation on a large scale, so that the competition would be between Chinese robots and American robots. The geopolitics of the coming decades could be understood as a competition towards singularity under names such as sinofuturism and Asian futurism.

It is within the desire for technological singularity, which conceals the ultimate dream of all forms of prometheanism, that we observe histories converging further on the same axis of time, moving towards a single direction and the realization of the homo deus. Coincidently, this convergence resonates with the progress of history as theodicy in the sense of Leibniz, as Hegel famously claimed. Digital studies must not relinquish this question too quickly and analyze only phenomena produced by new industrial technologies. Instead, it is necessary to open new directions for the development of digital technology in order to imagine a future with technical diversities.

As with the first problem, in which the future is already determined through calculation, which commands $\tau \dot{\alpha} \pi \dot{\alpha} \nu \tau \alpha$ like the lightening of Heraclitus, time in the second problem is constrained by a world history presented as a single time axis, in which the present is always already determined by a future imposed as necessity. World history, in this understanding, follows a defined order: premodern, modern, postmodern, 
apocalypse. I would like to argue that modernization is a synchronization based on a universalist concept of technology that confuses universalism with universalization, with the latter being inseparable from colonization qua technological globalization. We are confronted with a homogenous technological future, which nurtures fanaticism as well as the fanaticism of speculation. This unquestioned universalism of technology must be exposed to its limit so that we can imagine a plurality of technological futures and therefore reopen the question of technology and hence imagine a new geopolitics and a new globalization to come.

\section{Antinomy of the Universality of Technology}

Conceiving the possibility of techno-diversity, I suggest, is possible only by breaking away from the synchronization described above to envisage different technological futures. This, in turn, is possible only if we recognize the plurality of cosmotechnics, a term that I coined to distance us from the impression that technology is universal. Here is a primary definition of cosmotechnics: the unification of the cosmic and moral orders through technical activities. This conceptualization is based on an antinomy of the universality of technology addressed in my recent book, The Question Concerning Technology in China: An Essay in Cosmotechnics, which could be stated:

Thesis: technology is an anthropological universal, understood as the exteriorization of memory and liberation of bodily organs, as some anthropologists and philosophers of technology have formulated.

Antithesis: technology is not anthropologically universal, being enabled and constrained by particular cosmologies, which go beyond functionalities and utilities. ${ }^{14}$

The peculiarity of the Kantian antinomy is that each thesis holds on its own but opposes the other; such an antinomy must be resolved by a form of thinking beyond universality and particularity. Synchronization relies on the thesis and undermines the antithesis. To answer the question concerning futurity, we must clarify the antithesis before a resolution can emerge. This is why I propose that each culture should develop its own history of cosmotechnics by systematically rediscovering and formulating its epistemologies and tracing the history of its epistemes in response to our current historical moment. The aim of conceptualizing cosmotechnics 
is to reopen the question of technics that was unfortunately closed down in past centuries.

Following the analysis in Heidegger's 1949 lecture later published as "Die Frage nach der Technik," we find two concepts and essences of technics. ${ }^{15}$ The first is the Greek techne, which means poiesis, or bringing forth (Hervorbringen), and the second is modern technology, the essence of which is no longer the Greek technē but rather enframing (Gestell), meaning that everything is considered calculable and exploitable as resources (Bestand). Gestell stands as the symbol of the modern, in which cosmologies are replaced with astrophysics. However, this discourse of technology is fundamentally European. While it is difficult, if not impossible, to position other kinds of technics - for example, the Chinese, Indian, or Amazonian — without reducing them to Greek technē, it is self-evident that they are not "modern" technologies.

Therefore, we need a new way of understanding technologies outside of Europe because they are neither technē nor modern technology. It is intriguing to hear non-European philosophers, when explain the origin of technologies in their cultures, refer immediately to the mythology of Prometheus, as if the Greek technē were the origin of all technics. This reference is symptomatic in the sense that it means a disorientation, in the double sense of the word. Historians of technology often compare the advancement of a particular technology in different cultures, for example, papermaking in China and Europe, or the dynamic of technical systems in China and Europe, as the French historian Bertrand Gilles has done. However, it is also possible that these comparisons easily circumvent the antinomy that we have raised above, namely the cosmological and metaphysical specificity of cosmotechnics. The question of technological futures must be approached through historical and metaphysical investigations of cosmotechnics - a task I have suggested carrying out by reconstructing a Chinese technological thought.

I attempted to do so by tracing the relation between dao (道) and $q i$ ( 器) in Confucianism, Neo-Confucianism and New Confucianism through a characterization of the dynamics between these two metaphysical categories as different epistemes. Dao literally means path, and $q i$, utensils (not to be confused with the $q i$ or ch'i [氣] usually translated as energy). Dao is a moral cosmological thinking that situates humans as cosmological beings and leads them toward the good. The unification of $q i$ and dao is neither a formula nor a static being; rather, it is dynamic and corresponds to the episteme of the epoch. I won't be able to elaborate on this development. And if I have attempted to diversify the concept of technics, it is because 
I want to put forward the following questions: Is it possible to take this historical moment to rethink digital technology, not only to understand its transformative power in new social phenomena but also to open up the question of technology and technodiversity? Is it possible to nourish digital technologies with new epistemologies and epistemes in light of the concept cosmotechnics?

Let us return to the two problems of temporality that we have aimed to sketch out in this paper. We see how digital technology interacts with other orders of temporal magnitude and have attempted to problematize these observations. I emphasize problems because these are what allow us to invent. The future already contained in preemptive algorithms is a battlefield for the studies of ethics and technology; to engage with the question posed by this future, I think it is important to unfold the epistemological and ontological presuppositions of these algorithms in order to put forward alternatives. We have also challenged the universalist concept of technology and proposed that in order to break from such technological determinism, it is necessary to reopen the question of technodiversity, which is also the condition of noodiversity. Therefore, we must be critical with notions of the future of humanity presented as the realization of homo deus or the progress of modernity. By rejecting the linear path attached to the image of technological progress, we also reject the politics of acceleration as the only option available for resolving social and political problems. We seek to allow multiple futures to emerge and remain irreducible to the global axis of time perceived as world history since what is called modernity.

\section{Notes}

1. See Yuk Hui, On the Existence of Digital Objects (Minneapolis: University of Minnesota Press, 2015), 29-32.

2. See Curtis Roads, Microsound (Cambridge, MA: MIT Press, 2004).

3. For more on interobjective relations, see my chapter "The Time of Technical Systems," in On the Existence of Digital Objects, 151-186.

4. See Martin Heidegger, Being and Time, trans. John Macquarrie and Edward Robinson (New York: Harper \& Row, 1962).

5. $\quad$ Edmund Husserl, The Phenomenology of Internal Time Consciousness, trans. J. S. Churchill (Bloomington: Indiana University Press, 2019).

6. See Stiegler, Technics and Time, 2: Disorientation, trans. Stephen Barker (Stanford, CA: Stanford University Press, 2009).

7. Jacques Derrida, "Différance," in Margins of Philosophy, trans. Alan Bass (Chicago: University of Chicago Press, 1982), 15. 
8. Gilles Deleuze, Difference and Repetition, trans. Paul Patton (New York: Columbia University Press, 1994).

9. See Jacques Ellul, The Technological System, trans. Joachim Neugroschel (Eugene, OR: Wipf \& Stock, 2018).

10. See "Logic and Time," in On the Existence of Technical Objects, 221-252.

11. For more, see Yuk Hui and Harry Halpin, "Collective Individuation: The Future of the Social Web," in Unlike Us Reader: Social Media Monopolies and Their Alternatives, ed. Geert Lovink and Miriam Rasch (Amsterdam: Institute of Network Cultures, 2013), 103-116.

12. Antoinette Rouvroy, "The End(s) of Critique: Data Behaviourism versus Due Process," in Privacy, Due Process and the Computational Turn (London: Routledge, 2013), 157-182.

13. Yuval Noah Harari, Homo Deus: A Brief History of Tomorrow (London: Vintage, 2016).

14. Yuk Hui, The Question Concerning Technology in China: An Essay in Cosmotechnics (Cambridge, MA, and London: MIT Press, 2019).

15. Martin Heidegger, "The Question Concerning Technology," in The Question Concerning Technology and Other Essays, trans. William Lovitt (New York: Garland, 1977), 3-35.

\section{About the Author}

Yuk Hui is the author of On the Existence of Technical Objects (Minnesota, 2016), The Question Concerning Technology in China: An Essay on Cosmotechnics (MIT, 2017), and Recursivity and Contingency (Rowman \& Littlefield, 2019). 
